\title{
Association between Maximal Oxygen Uptake and the Heart Rate Corrected-QT Interval in Postmenopausal Overweight Women
}

\author{
Ryoma Michishita $^{1}$, Naoko Shono ${ }^{2,3}$, Takaki Kasahara ${ }^{1}$, and Toshiyuki Tsuruta ${ }^{1}$ \\ ${ }^{1}$ Clinic of Tsuruta Orthopaedic Surgery, Saga, Japan \\ ${ }^{2}$ Institute of Lifestyle Medical Science, Saga, Japan \\ ${ }^{3}$ Department of Rehabilitation Science, Nishikyushu University, Saga, Japan
}

Background: Increased aerobic capacity can reduce the incidence of cardiovascular disease and the mortality rate. On the other hand, a prolonged heart rate corrected-QT $(\mathrm{QTc})$ interval is associated with an increased risk of arrhythmias, cardiac sudden death and coronary artery disease.

Aims: The association of the aerobic capacity and coronary risk factors with QTc interval was investigated in postmenopausal overweight women.

Subjects and Methods: The subjects included 84 postmenopausal overweight women [age: $58.7 \pm 6.4$ years, body mass index (BMI): 27.9 \pm 3.3 ] with coronary risk factors. Electrocardiogram (ECG) was recorded with a standard resting 12-lead ECG after more than 5 minutes of rest. The QTc interval was automatically calculated according to Bazett's formula. A multistage graded submaximal exercise test was performed on an electric bicycle ergometer to determine the estimated maximal oxygen uptake ( $\dot{\mathrm{V}}_{2}$ max $)$.

Results: Single correlation analysis showed the QTc interval to be positively associated with hemoglobin $A_{1 c}\left(\mathrm{HbA}_{1 \mathrm{c}}\right)$, fasting glucose, fasting insulin, BMI, waist circumference, serum potassium and the number of coronary risk factors, while negatively correlated with $\dot{\mathrm{V}}_{2}$ max. Stepwise multiple regression analysis demonstrated the strong association of the QTc interval with $\mathrm{HbA}_{1} \mathrm{c}$ and $\dot{\mathrm{VO}}_{2}$ max $\left(r^{2}=0.244, p<0.0001\right)$. In both patients with and without metabolic syndrome $(n=15, n=69$, respectively), the QTc interval was independently associated with the $\mathrm{HbA} 1 \mathrm{c}\left(r^{2}=0.318, p<0.05, r^{2}=\right.$ $0.115, p<0.05$, respectively).

Conclusions: These results suggest that decreased aerobic capacity and glucose intolerance may be independent risk factors for a prolonged QTc interval, while demonstrating no relationship with metabolic syndrome.

JAtheroscler Thromb, 2009; 16:396-403.

Key words; Heart rate-corrected QT interval, Maximal oxygen uptake, Electrolyte imbalance, Metabolic syndrome, Glucose intolerance

\section{Introduction}

Physical inactivity and decreased aerobic capacity are associated with a significantly higher incidence of coronary artery disease $(\mathrm{CAD})^{1,2}$. Conversely, habitual exercise training can control the incidence of

Address for correspondence: Ryoma Michishita, Clinic of Tsuruta Orthopaedic Surgery, 174-8 Kamitogawa Ushizumachi, Saga 849-0305, Japan

E-mail: rheuma.clinic.21@lime.ocn.ne.jp

Received: October 21, 2008

Accepted for publication: January 29, 2009
$\mathrm{CAD}^{1,2)}$. In addition, several studies have demonstrated that the risk of CAD increased in line with the accumulation of coronary risk factors such as visceral fat accumulation, diabetes mellitus, hypertension and dyslipidemia $^{3,4)}$.

On the other hand, a prolonged heart rate corrected-QT (QTc) interval, as measured with a standard electrocardiogram (ECG), is associated with an increased risk of arrhythmias, cardiac sudden death, CAD, left ventricular hypertrophy (LVH) and cardiac autonomic nervous system dysfunction ${ }^{5-9)}$. Specifically, the QTc interval is longer in women than in 
men and it is also influenced by age, sex hormones and an electrolyte imbalance dysfunction ${ }^{6,10)}$. Previous studies have reported that morbid obesity is also correlated with a prolonged QTc interval ${ }^{11,12)}$. Several studies have observed that weight loss could improve the QTc in obese subjects ${ }^{12-14)}$. These results suggest that the resolution of obesity by diet or exercise can therefore help to improve the autonomic nervous system, arrhythmia, LVH, prevention of cardiac sudden death and coronary artery disease. However, the associations between either aerobic capacity or the accumulation of coronary risk factors and the QTc interval are still unknown, despite the observation that lower aerobic capacity and the accumulation of coronary risk factors influences the development of $\mathrm{CAD}$ and other ECG abnormalities ${ }^{1,2,15)}$.

This study was designed to clarify the associations of aerobic capacity and coronary risk factors with the QTc interval in postmenopausal overweight women. The hypothesis is that reduced aerobic capacity may be a sensitive factor for predicting a prolonged QTc interval and electrolyte imbalance dysfunction. The resting ECG, blood sampling and exercise test as screening tests are therefore considered to be important for preventing the incidence of CAD and cardiac sudden death in overweight subjects. As mentioned above, a prolonged QTc interval is a good predictor of CAD and cardiac sudden death. Therefore, the linkage between aerobic capacity and coronary risk factors with the QTc interval may be useful for detecting early stage CAD and cardiac sudden death in overweight subjects. We focused on subjects to be only postmenopausal overweight women to exclude the influence of sex differences and hormones.

\section{Subjects and Methods}

\section{Subjects}

This study enrolled 84 postmenopausal obese women (age: $58.7 \pm 6.4$ years, BMI: $27.9 \pm 3.3 \mathrm{~kg} / \mathrm{m}^{2}$ ) with coronary risk factors, including hypertension, impaired glucose tolerance, or dyslipidemia. Those taking cardioactive drugs, such as anti-hypertensive drugs, statins or hypoglycemic agents, or patients with a history of cerebrovascular disease, CAD, LVH, cardiac valve disease, or diabetic complications (diabetic neuropathy, diabetic nephropathy and diabetic retinopathy) or an electrolyte disturbance, bundle branch block, intraventricular conduction disturbance, abnormal Q wave, abnormal ST-T wave and a regular smoking habit, were excluded. The local institutional review board approved the study protocol and written informed consent was obtained from each patient prior to commencement of the study.

\section{Resting ECG, Blood Sampling and Anthropometric Measurements}

ECG was recorded with a standard resting 12lead ECG (FCP-2155, Fukuda Denshi, Tokyo, Japan) at a paper speed of $25 \mathrm{~mm}$ per second after more than 5 minutes of rest. The QTc interval was automatically calculated according to Bazett's formula ${ }^{16)}$ (QTc interval $=\mathrm{QT}$ interval/square root of R-R interval).

Blood samples were collected early in the morning by venipuncture from an antecubital vein, after at least a $12 \mathrm{hr}$ fast. The fasting blood samples were used to measure the following parameters: high-density lipoprotein cholesterol (HDL-C) by the direct method, low-density lipoprotein cholesterol (LDL-C), triglyceride and plasma glucose by enzymatic methods, serum insulin by the enzyme immunoassay method, hemoglobin $\mathrm{A}_{1 \mathrm{c}}\left(\mathrm{HbA}_{1 \mathrm{c}}\right)$ by high performance liquid chromatography, and serum sodium and potassium by the electrode method. Abdominal obesity (waist circumference: $\geq 90 \mathrm{~cm}$ ), hyperglycemia (fasting glucose: $\geq 110 \mathrm{mg} / \mathrm{dL}$ ), dyslipidemia (HDL-C: $<40 \mathrm{mg} / \mathrm{dL}$ and/or fasting triglyceride: $\geq 150 \mathrm{mg} / \mathrm{dL}$ ) and normal high blood pressure (resting systolic blood pressure: $\geq 130 \mathrm{mmHg}$ and/or resting diastolic blood pressure: $\geq 85 \mathrm{mmHg}$ ) were defined as coronary risk factors, and the total number of risk factors was also calculated for each subject. Metabolic syndrome was defined according to the metabolic syndrome diagnostic criteria in Japan ${ }^{17,18)}$.

The height and body weight were measured, while BMI was calculated as the ratio of the body weight $(\mathrm{kg})$ divided by the height squared $\left(\mathrm{m}^{2}\right)$. Waist circumference was measured at the level of the umbilicus.

\section{Exercise Test}

A multistage graded submaximal exercise stress test was performed on each subject using an electric bicycle ergometer. The workload was increased every 4 minutes, depending on their daily activity levels. A CM5-lead ECG (ML-1800; Fukuda Denshi) was recorded continuously during exercise testing. The following parameters were measured at rest and during the last minute of each stage: the rate of perceived exhaustion, blood pressure (FB-300; Fukuda Denshi) and blood lactate concentration (Lactate Pro; Arkray). Maximal oxygen uptake $\left(\dot{\mathrm{VO}}_{2} \max \right)$ was estimated by the nomogram of Astrand and Ryhming ${ }^{19)}$, using the heart rate measured at three different submaximal workloads. The end point of exercise testing was determined on the basis of either achieving a blood lactate 
concentration $\geq 4 \mathrm{mmol} / \mathrm{L}$ or the criteria described in the guidelines of the American College of Sports Medicine ${ }^{20)}$. The subjects were divided into three categories, which were defined as equally trisected distributions of the $\dot{\mathrm{V}}{ }_{2} \max$ [low $(15.3-24.4 \mathrm{~mL} / \mathrm{kg} / \mathrm{min})$, moderate $(24.6-28.2 \mathrm{~mL} / \mathrm{kg} / \mathrm{min})$ and high $\left(28.3^{-}\right.$ $38.9 \mathrm{~mL} / \mathrm{kg} / \mathrm{min})$ ].

\section{Statistical Analysis}

Data are expressed as the means \pm SD. Statistical analyses were performed using the StatView software package. Inter-group comparisons were performed using the unpaired $t$-test for continuous variables. The inter-multiple group relationships were determined using one-way repeated measure analysis of variance (ANOVA) and the Tukey-Kramer method. Pearson's univariate regression and stepwise multivariate regression analyses were performed in order to determine the association of the QTc interval with the $\dot{\mathrm{VO}}_{2}$ max and coronary risk factors. A probability value of $<0.05$ was considered significant.

\section{Results}

Table 1 shows patient characteristics, and Fig. 1 compares the QTc interval and electrolyte indices among the low, moderate and high $\dot{\mathrm{VO}}_{2}$ max groups. The QTc interval was significantly longer in the low $\dot{\mathrm{V}}{ }_{2}$ max group than in the high $\dot{\mathrm{VO}}_{2}$ max group (428.9 \pm 23.5 vs. $425.0 \pm 20.7$ vs. $414.7 \pm 17.0 \mathrm{msec}, p<0.05$ ). Serum sodium was significantly higher $(142.1 \pm 1.6$ vs. $141.1 \pm 1.4$ vs. $140.4 \pm 1.9 \mathrm{mEq} / \mathrm{L}, p<0.01$ ), while serum potassium was significantly lower in the low $\dot{\mathrm{VO}} 2$ max group than in the high $\dot{\mathrm{VO}} 2$ max group (4.0 \pm 0.3 vs. $4.1 \pm 0.3$ vs. $4.2 \pm 0.3 \mathrm{mEq} / \mathrm{L}, p<0.05)$. Table 2 compares patients characteristics between low, moderate and high $\dot{\mathrm{VO}}_{2}$ max groups. $\mathrm{HbA}_{1 \mathrm{c}}$, fasting glucose, fasting insulin levels and diastolic blood pressure were significantly higher in the low $\dot{\mathrm{VO}} 2$ max group than in the high $\dot{\mathrm{VO}}_{2}$ max group $(p<0.05$, respectively). BMI was significantly higher in the low $\mathrm{VO}_{2}$ max group than in moderate and high $\dot{\mathrm{VO}}_{2}$ max groups $(p<0.05$, respectively). Waist circumference was significantly higher (low $<$ moderate $<$ high) and $\dot{\mathrm{V}} \mathrm{O}_{2}$ max was significantly lower in high, moderate and low $\dot{\mathrm{VO}}_{2}$ max groups [(high $<$ moderate $<$ low), $p<0.05$, respectively]. The number of coronary risk factors was significantly higher in low and moderate $\dot{\mathrm{VO}}_{2}$ max groups than in the high $\dot{\mathrm{V}}{ }_{2} \max$ group. In addition, Fig. 2 shows comparisons of the QTc interval and electrolyte indices between patients with and without metabolic syndrome. In patients with metabolic syndrome, QTc interval $(435.5 \pm 19.0$ vs. $419.6 \pm 20.6 \mathrm{msec}, p<0.01)$
Table 1. Patient characteristics

\begin{tabular}{lc}
\hline Age (years) & $58.7 \pm 6.4$ \\
HDL-C $(\mathrm{mg} / \mathrm{dL})$ & $59.8 \pm 12.1$ \\
LDL-C $(\mathrm{mg} / \mathrm{dL})$ & $135.4 \pm 30.0$ \\
Triglyceride $(\mathrm{mg} / \mathrm{dL})$ & $115.8 \pm 62.1$ \\
HbAıc $(\%)$ & $5.3 \pm 0.7$ \\
Fasting glucose $(\mathrm{mg} / \mathrm{dL})$ & $97.8 \pm 18.6$ \\
Fasting innsulin $(\mu \mathrm{U} / \mathrm{mL})$ & $8.7 \pm 5.3$ \\
Serum sodium $(\mathrm{mEq} / \mathrm{L})$ & $141.2 \pm 1.8$ \\
Serum potassium $(\mathrm{mEq} / \mathrm{L})$ & $4.1 \pm 0.3$ \\
BMI (kg/m $\left.{ }^{2}\right)$ & $27.9 \pm 3.3$ \\
Waist circumference $(\mathrm{cm})$ & $90.0 \pm 8.8$ \\
Resting systolic blood pressure $(\mathrm{mmHg})$ & $121.8 \pm 16.2$ \\
Resting diastolic blood pressure $(\mathrm{mmHg})$ & $80.3 \pm 10.2$ \\
Resting heart rate $($ beats/min) & $68.2 \pm 10.0$ \\
RR interval (msec) & $891.4 \pm 135.7$ \\
QT interval (msec) & $400.1 \pm 29.7$ \\
QTc interval (msec) & $422.9 \pm 21.2$ \\
VO 2 max (mL/min/kg) & $26.3 \pm 4.5$ \\
Number of coronary risk factors & $1.7 \pm 0.8$ \\
\hline
\end{tabular}

Data are expressed as the mean $\pm \mathrm{SD}, \mathrm{HDL}-\mathrm{C}=$ high-density lipoprotein cholesterol, LDL-C $=$ low-density lipoprotein cholesterol, $\mathrm{HbA}_{1 \mathrm{c}}$ $\mathrm{A}_{1 \mathrm{c}}, \mathrm{BMI}=$ body mass index, $\mathrm{QTc}=$ haert rate corrected $\mathrm{QT}$ interval, $\dot{\mathrm{V}}{ }_{2} \max =$ maximum oxygen uptake. Abdominal obesity, hyperglycemia, dyslipidemia and normal high blood pressure were defined as coronary risk factors, and the total number of risk factors was also calculated for each subject.

was significantly longer and serum sodium $(141.8 \pm 1.5$ vs. $140.1 \pm 1.8 \mathrm{mEq} / \mathrm{L}, p<0.05$ ) was significantly higher than in patients without metabolic syndrome.

Table 3 shows the association between the QTc interval and coronary risk factors, determined by univariate regression analysis in all patients, with and without metabolic syndrome. In all patients, the QTc interval correlated positively with $\mathrm{HbA}_{1 \mathrm{c}}(r=0.452$, $p<0.0001)$, fasting glucose $(r=0.410, p<0.0001)$, fasting insulin $(r=0.255, p<0.05)$, BMI $(r=0.262$, $p<0.05)$, waist circumference $(r=0.292, p<0.01)$, the number of coronary risk factors $(r=0.331, p<0.01)$ and negatively with serum potassium $(r=-0.231, p<$ $0.05)$ and $\dot{\mathrm{VO}}_{2} \max (r=-0.294, p<0.01)$. In patients with metabolic syndrome $(n=15)$, QTc interval correlated positively with $\mathrm{HbA}_{1 \mathrm{c}}(r=0.563, p<0.05)$, fasting glucose $(r=0.542, p<0.05)$, fasting insulin $(r=$ $0.521, p<0.05)$, serum sodium $(r=0.516, p<0.05)$ and negatively with $\dot{\mathrm{VO}}_{2} \max (r=-0.515, p<0.05)$. In patients without metabolic syndrome $(n=69)$, QTc interval correlated positively with $\mathrm{HbA}_{1 \mathrm{c}}(r=0.339$, $p<0.01)$, fasting glucose $(r=0.279, p<0.05)$, fasting insulin $(r=0.236, p<0.05)$, BMI $(r=0.267, p<0.05)$, waist circumference $(r=0.257, p<0.05)$ and negatively 
A)

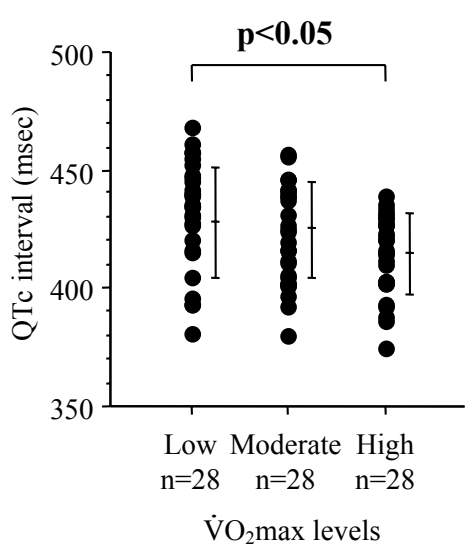

B)

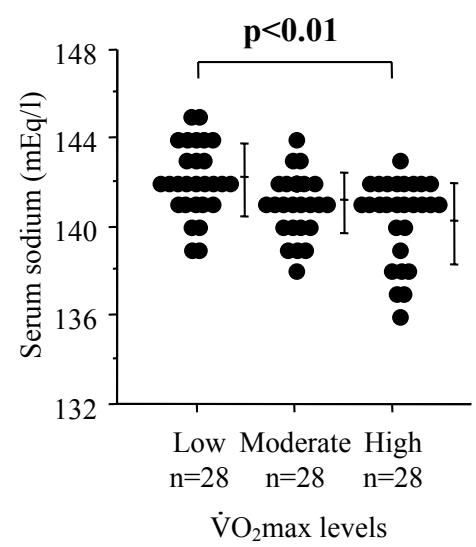

C)

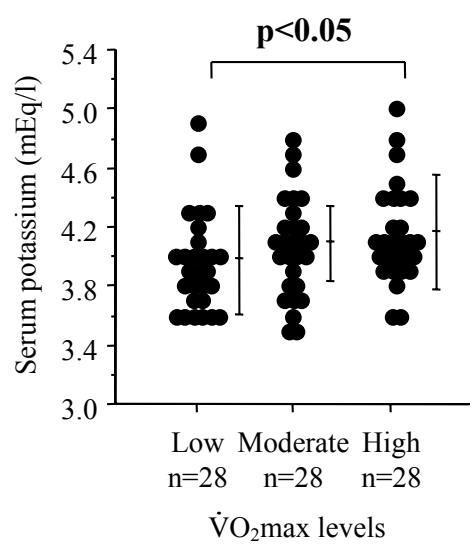

Fig. 1. Difference in the QTc interval (A) and electrolyte indices [serum sodium (B) and potassium (C)] in the low $(n=28,15.3-24.4 \mathrm{~mL} / \mathrm{kg} / \mathrm{min})$, moderate $(n=28,24.6-28.2 \mathrm{~mL} / \mathrm{kg} / \mathrm{min})$ and high $\dot{\mathrm{V}} \mathrm{O}_{2}$ max groups $(n=28,28.3-38.9 \mathrm{~mL} / \mathrm{kg} / \mathrm{min})$.

The results are shown as the means $\pm \mathrm{SD}$.

Table 2. Differences in coronary risk factors in low, moderate and high $\dot{\mathrm{V}} \mathrm{O}_{2}$ max groups

\begin{tabular}{lccc}
\hline & $\begin{array}{c}\text { Low }(n=28) \\
(15.3-24.4 \mathrm{~mL} / \mathrm{kg} / \mathrm{min})\end{array}$ & $\begin{array}{c}\text { Moderate }(n=28) \\
(24.6-28.2 \mathrm{~mL} / \mathrm{kg} / \mathrm{min})\end{array}$ & $\begin{array}{c}\text { High }(n=28) \\
(28.3-38.9 \mathrm{~mL} / \mathrm{kg} / \mathrm{min})\end{array}$ \\
\hline$\dot{\mathrm{V}} \mathrm{O}_{2 \mathrm{max}}(\mathrm{mL} / \mathrm{kg} / \mathrm{min})$ & $21.8 \pm 2.8^{*}, \dagger$ & $25.9 \pm 1.1^{*}$ & $31.2 \pm 2.7$ \\
$\mathrm{Age}($ years & $58.4 \pm 5.3$ & $59.4 \pm 6.9$ & $58.2 \pm 7.0$ \\
$\mathrm{HDL}-\mathrm{C}(\mathrm{mg} / \mathrm{dL})$ & $56.5 \pm 10.4$ & $59.5 \pm 12.1$ & $63.3 \pm 13.2$ \\
$\mathrm{LDL}-\mathrm{C}(\mathrm{mg} / \mathrm{dL})$ & $137.6 \pm 34.5$ & $132.6 \pm 28.9$ & $135.8 \pm 27.1$ \\
Triglyceride $(\mathrm{mg} / \mathrm{dL})$ & $125.9 \pm 54.0$ & $125.0 \pm 84.6$ & $96.5 \pm 34.6$ \\
$\mathrm{HbA1c}(\%)$ & $5.5 \pm 0.8^{*}$ & $5.4 \pm 0.7$ & $5.1 \pm 0.3$ \\
Fasting glucose $(\mathrm{mg} / \mathrm{dL})$ & $103.0 \pm 24.8^{*}$ & $97.8 \pm 15.0$ & $90.6 \pm 9.8$ \\
Fasting insulin $(\mu \mathrm{U} / \mathrm{mL})$ & $10.5 \pm 7.3^{*}$ & $9.0 \pm 4.1$ & $6.6 \pm 2.7$ \\
$\mathrm{BMI}\left(\mathrm{kg} / \mathrm{m}^{2}\right)$ & $30.5 \pm 3.7^{*, \dagger}$ & $27.4 \pm 2.3$ & $25.9 \pm 1.4$ \\
Waist circumference $(\mathrm{cm})$ & $95.8 \pm 8.2^{*}$, & $89.6 \pm 8.0^{*}$ & $84.7 \pm 6.6$ \\
Resting systolic blood pressure $(\mathrm{mmHg})$ & $121.9 \pm 16.0$ & $125.8 \pm 17.0$ & $117.7 \pm 15.1$ \\
Resting diastolic blood pressure $(\mathrm{mmHg})$ & $83.2 \pm 11.7^{*}$ & $80.6 \pm 8.5$ & $77.2 \pm 9.7$ \\
The number of coronary risk factors & $2.0 \pm 0.9^{*}$ & $1.8 \pm 0.9^{*}$ & $1.2 \pm 0.5$ \\
\hline
\end{tabular}

Data are expressed as the mean \pm SD. ${ }^{*} ; p<0.05$, Compared with high group. ${ }^{\dagger} ; p<0.05$, Compared with moderate group. Abbreviations as in Table 1.

with serum potassium $(r=-0.237, p<0.05)$.

In stepwise multivariate regression analysis, the QTc interval was used as a continuous variable, and was entered as a dependent variable. The following factors were entered as independent variables: age, HbAic, fasting insulin, waist circumference, serum sodium, serum potassium, $\dot{\mathrm{V}} \mathrm{O}_{2}$ max and the number of coronary risk factors. This analysis showed that the QTc interval was associated independently with the $\mathrm{HbA}_{1 \mathrm{c}}$ and $\dot{\mathrm{V}} \mathrm{O}_{2} \mathrm{max}$ in all patients $\left(r^{2}=0.244, p<\right.$ $0.0001)$. In both patients with and without metabolic syndrome, the QTc interval was associated indepen- dently with the $\mathrm{HbA}_{1 \mathrm{c}}\left[r^{2}=0.318, p<0.05, r^{2}=0.115\right.$, $p<0.05$, respectively (Table 4)].

\section{Discussion}

The major finding of this study was that the QTc interval and serum sodium were higher and the serum potassium was lower in the low $\dot{\mathrm{VO}}_{2}$ max group than in the high $\dot{\mathrm{V}}{ }_{2}$ max group. In addition, our stepwise multiple regression analysis showed the $\mathrm{HbA}_{1 \mathrm{c}}$ and $\dot{\mathrm{V}} \mathrm{O}_{2} \mathrm{max}$ to be more powerfully associated with the QTc interval than other risk factors. In the 
A)

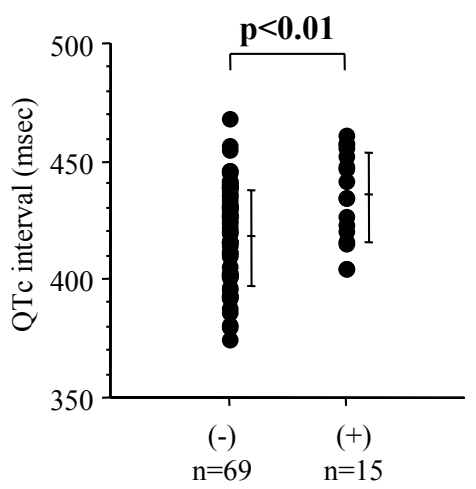

Metabolic Syndrome
B)

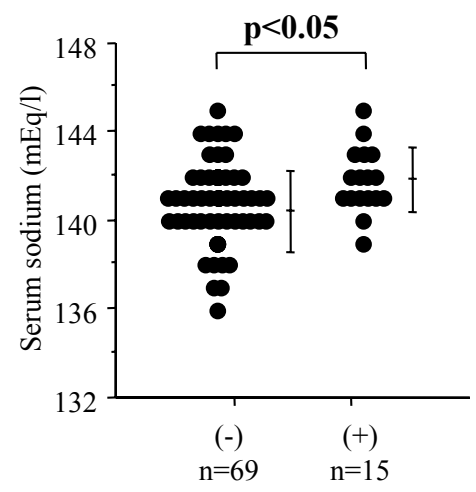

Metabolic Syndrome
C)

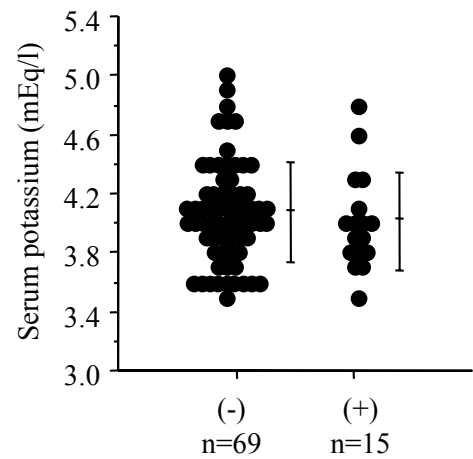

Metabolic Syndrome

Fig. 2. Difference in the QTc interval (A) and indices of electrolyte [serum sodium (B) and potassium (C)] between patients with $(n=15)$ and without $(n=69)$ metabolic syndrome.

The results are shown as the means $\pm S D$. Metabolic syndrome was defined according to the metabolic syndrome diagnostic criteria in Japan ${ }^{17,18)}$.

Table 3. Association between QTc interval and coronary risk factors calculated by simple regression analysis in all patients, with and without metabolic syndrome

\begin{tabular}{lccc}
\hline & & \multicolumn{2}{c}{ Metabolic Syndrome } \\
\cline { 3 - 4 } & & $(+)$ & $(-)$ \\
\hline Age & 0.040 & 0.062 & 0.042 \\
HDL-C & -0.004 & -0.133 & -0.015 \\
LDL-C & 0.057 & 0.397 & 0.109 \\
Triglyceride & 0.060 & 0.285 & 0.028 \\
HbAic & $0.452^{* *}$ & $0.563^{\dagger}$ & $0.339^{*}$ \\
Fasting glucose & $0.410^{* *}$ & $0.542^{\dagger}$ & $0.279^{\dagger}$ \\
Fasting insulin Fasting insulin & $0.255^{\dagger}$ & $0.521^{\dagger}$ & $0.236^{\dagger}$ \\
BMI & $0.262^{\dagger}$ & 0.109 & $0.267^{\dagger}$ \\
Waist circumference & $0.292^{*}$ & 0.146 & $0.257^{\dagger}$ \\
Resting systolic blood pressure & 0.163 & 0.089 & 0.069 \\
Resting diastolic blood pressureg & 0.045 & 0.013 & 0.204 \\
Serum sodium & 0.123 & $0.516^{\dagger}$ & 0.002 \\
Serum potassium & $-0.231^{\dagger}$ & -0.404 & $-0.237^{\dagger}$ \\
VOzmax & $-0.294^{*}$ & $-0.515^{\dagger}$ & -0.122 \\
Number of coronary risk factors & $0.331^{*}$ & 0.119 & 0.044 \\
\hline
\end{tabular}

Data are expressed as the coefficient of correlation. ${ }^{\dagger} ; p<0.05,{ }^{*} ; p<0.01,{ }^{* *} ; p<0.0001$. Abbreviations as in Table 1.

current study, the QTc interval was significantly associated with obesity indices and glucose metabolism indices and those findings were consistent with previous studies $5,7,8,11,21$. However, the association between the $\dot{\mathrm{V}}{ }_{2} \max$ and QTc interval remains unknown, despite the observation that a lower aerobic capacity influences the development of diabetes mellitus, CAD and ECG abnormalities ${ }^{1-4,15,18,22)}$.

According to our data, the indices of glucose metabolism, obesity, blood pressure and the number of coronary risk factors were significantly higher in the low $\dot{\mathrm{VO}}_{2}$ max group than in the high $\dot{\mathrm{VO}}_{2}$ max group. Furthermore, our stepwise multiple regression analysis showed $\mathrm{HbA}_{1}$ to be strongly associated with the QTc interval, while it showed no relation to metabolic syndrome. It has been reported ${ }^{22)}$ that reduced aerobic capacity and physical inactivity influences the development of diabetes mellitus, metabolic syndrome and 
Table 4. Association between QTc interval and coronary risk factors calculated by stepwise multip regression analysis in all patients, with and without metabolic syndrome

\begin{tabular}{|c|c|c|c|c|c|c|}
\hline & \multicolumn{2}{|c|}{ All patients } & \multicolumn{4}{|c|}{ Metabolic Syndrome } \\
\hline & $\beta$ & $p$ vallue & $\beta$ & $p$ vallue & $\beta$ & $p$ vallue \\
\hline Age & 0.025 & NS & 0.051 & NS & 0.031 & NS \\
\hline $\mathrm{HbA}_{1 \mathrm{c}}$ & 0.423 & $p<0.0001$ & 0.563 & $p<0.05$ & 0.339 & $p<0.05$ \\
\hline Serum sodium & 0.031 & NS & 0.337 & NS & 0.051 & NS \\
\hline Serum potassium & -0.201 & NS & -0.332 & NS & -0.184 & NS \\
\hline$\dot{\mathrm{VO}}_{2} \max$ & -0.210 & $p<0.0001$ & -0.351 & NS & -0.100 & NS \\
\hline Number of coronary risk factors & 0.111 & NS & 0.144 & NS & -0.183 & NS \\
\hline$r^{2}$ & 0.244 & & 0.318 & & 0.115 & \\
\hline
\end{tabular}

$\beta$; standard regression coefficient. In stepwise multiple regression analysis the QTc interval was entered as dependent variable. The following factors were entered as independent variables: age, $\mathrm{HbA}_{1 \mathrm{c}}$, fasting insulin, waist circumference, serum sodium, serum potassium, $\dot{\mathrm{VO}}_{2}$ max and the number of coronary risk factors.

CAD. Several studies have demonstrated ${ }^{4,18)}$ that metabolic syndrome was also associated with an increased risk of future diabetes mellitus and CAD. Recently, the association between a prolonged QTc interval and ischemic heart disease has been clearly demonstrated $^{5-7)}$. Although none of the patients underwent coronary angiography, some might possibly have had occult atherosclerotic coronary artery disease. Abnormal glucose metabolism is considered to be associated with micro-vessel coronary artery disease ${ }^{23)}$, which might cause a prolonged QTc interval in some patients. Namely, continuing hyperglycemia involved lower aerobic capacity and increased coronary risk factors may be a good predictor of a prolonged QTc interval through myocardial ischemia.

In addition, sympathetic nervous system dysfunction is also known to influence a prolonged QTc interval $^{6,9)}$. Previous studies have reported that morbid obesity also correlates with sympathetic nervous system dysfunction ${ }^{24)}$. Moreover, the plasma catecholamine concentration is improved by endurance aerobic exercise training ${ }^{25}$.

Furthermore, the QTc interval is influenced by an electrolyte imbalance, such as a reduction in outward potassium channel currents or an increased in inward sodium or calcium channel currents ${ }^{26)}$. According to our data, fasting insulin was correlated positively with serum sodium $(r=0.258, p<0.05$, data not shown). In addition, the serum sodium level was higher and the serum potassium was lower in the low $\dot{\mathrm{VO}}_{2}$ max group than in the high $\dot{\mathrm{VO}}_{2}$ max group, and the serum sodium level was higher in patients with metabolic syndrome than in patients without metabolic syndrome. Previous studies have observed that insulin resistance or hyperinsulinemia promoted sodium reabsorption in the kidney ${ }^{27,28)}$. Moreover, the sodium/ potassium ratio in skeletal muscle in obese subjects with glucose intolerance and the potassium concentration in skeletal muscle is increased by aerobic endurance training ${ }^{29)}$.

Therefore, the association of reduced aerobic capacity, physical inactivity and glucose intolerance with a prolonged QTc interval might be caused by overactivity of the sympathetic nervous system, microvessel coronary artery disease and electrolyte imbalance dysfunction. The current findings suggest that decreases in aerobic capacity and glucose intolerance may be a predictive factor for indirectly detecting the development of a prolonged QTc interval in postmenopausal overweight women.

\section{Study Limitations and Clinical Implications}

There are several limitations related to this study. First, the limited study population resulted in small number of subjects, in patients without complications or on medications and with a predominance of middle-aged women. Therefore, it remains unclear whether our findings are consistent with premenopausal women or men, CAD patients and those with other complications. Second, since the study had a crosssectional design, it was not possible to clarify the causative role of the QTc interval on the $\dot{\mathrm{V}} \mathrm{O}_{2}$ max and other coronary risk factors. Finally, the $\dot{\mathrm{VO}}_{2} \max$ in this study was estimated using the nomogram of 
Atrand and Ryhming. However, the $\dot{\mathrm{VO}}_{2}$ max estimated by this method has been used in many large epidemiologic studies. Moreover, a prolonged QTc interval has been observed to be associated with future cardiac sudden death and coronary artery disease ${ }^{4-6)}$. Therefore, the results of the linkage between the QTc interval and $\dot{\mathrm{VO}}_{2}$ max combined with general coronary risk factors, such as glucose intolerance, may suggest the hypothesis that reduced aerobic capacity leads to future cardiac sudden death and CAD. Furthermore, additional research in a large number of subjects is required to more precisely clarify the mechanisms, clinical implications and associations between aerobic capacity and the QTc interval following exercise therapy.

\section{Notice of Grant Support}

This study was supported in part by a grant from the Japanese Ministry of Education, Culture, Sports, Science and Technology (No.16500445).

\section{References}

1) Manson JE, Greenland P, LaCroix AZ, Stefanick ML, Mouton CP, Oberman A, Perri MG, Sheps DS, Pettinger $\mathrm{MB}$, Siscovick DS: Walking compared with vigorous exercise for the prevention of cardiovascular events in women. N Engl J Med, 2002; 347: 716-725

2) Noda $H$, Iso $H$, Toyoshima $H$, Date $C$, Yamamoto $A$, Kikuchi S, Koizumi A, Kondo T, Watanabe Y, Wada Y, Inaba Y, Tamakoshi A; JACC Study Group: Walking and sports participation and mortality from coronary heart disease and stroke. J Am Coll Cardiol, 2005; 46: 17611767

3) Nakamura T, Tsubono Y, Kameda-Takemura K, Funahashi T, Yamashita S, Hisamichi S, Kita T, Yamamura T, Matsuzawa Y; Group of the Research for the Association between Host Origin and Atherosclerotic Disease under the Preventive Measure for Work-related Disease of the Japanese Labor ministry: Magnitude of sustained multiple risk factors for ischemic heart disease in Japanese employees. a case-control study. Jpn Circ J, 2001; 65: 11-17

4) Hitsumoto T, Takahashi M, Iizuka T, Shirai K: Relationship between metabolic syndrome and early stage coronary atherosclerosis. J Atheroscler Thromb, 2007; 14: 294302

5) Dekker JM, Schouten EG, Klootwijk P, Pool J, Kromhout D: Association between QT interval and coronary heart disease in middle-aged and elderly men. The Zutphen Study. Circulation, 1994; 90: 779-785

6) Straus SM, Kors JA, De Bruin ML, van der Hooft CS, Hofman A, Heeringa J, Deckers JW, Kingma JH, Sturkenboom MC, Stricker BH, Witteman JC: Prolonged QTc interval and risk of sudden cardiac death in a population of older adults. J Am Coll Cardiol, 2006; 47: 362367
7) Dekker JM, Crow RS, Hannan PJ, Schouten EG, Folsom AR; ARIC Study: Heart rate-corrected QT interval prolongation predicts risk of coronary heart disease in black and white middle-aged men and women: the ARIC study. J Am Coll Cardiol, 2004; 43: 565-571

8) Dekker JM, Feskens EJ, Schouten EG, Klootwijk P, Pool J, Kromhout D: QTc duration is associated with levels of insulin and glucose intolerance. The Zutphen Elderly Study. Diabetes, 1996; 45: 376-380

9) Festa A, D’Agostino RD Jr, Rautaharju P, Mykkänen L, Haffner SM: Relation of systemic blood pressure, left ventricular mass, insulin sensitivity and coronary artery disease to QT interval duration in nondiabetic and type 2 diabetic subjects. Am J Cardiol, 2000; 86: 1117-1122

10) Rautaharju PM, Zhou SH, Wong S, Chalhoun HP, Berenson GS, Prineas R, Davignon A: Sex differences in the evolution of the electrocardiographic QT interval with age. Can J Cardiol, 1992; 8: 690-695

11) el-Gamal A, Gallagher D, Nawras A, Gandhi P, Gomez J, Allison DB, Steinberg JS, Shumacher D, Blank R, Heymsfield SB: Effects of obesity on QT, RR and QTc intervals. Am J Cardiol, 1995; 75: 956-959

12) Carella MJ, Mantz SL, Rovner DR, Willis PW 3rd, Gossain VV, Bouknight RR, Ferenchick GS: Obesity, adiposity and lengthening of the QT interval: improvement after weight loss. Int J Obes Relat Metab Disord, 1996; 20: 938-942

13) Pietrobelli A, Rothacker D, Gallagher D, Heymsfield SB: Electrocardiographic QTC interval: short-term weight loss effects. Int J Obes Relat Metab Disord, 1997; 21: 110-114

14) Mshui ME, Saikawa T, Ito K, Hara M, Sakata T: QT interval and QT dispersion before and after diet therapy in patients with simple obesity. Proc Soc Exp Biol Med, 1999; 220: 133-138

15) Michishita R, Shono N, Kiyonaga A, Tanaka H, Shindo M, Kasahara T, Tsuruta T, Inoue T, Node K: Association between silent ST segment depression in exercise electrocardiography and insulin resistance in obese subjects. J Cardiol, 2007; 49: 231-239

16) Bazett HC: An analysis of time relations of electrocardiogram. Heart, 1920; 7: 353-370

17) Matsuzawa Y: Metabolic Syndrome-definition and diagnostic criteria in Japan. J Jpn Soc Int Med, 2005; 94 : 794-809

18) Teramoto T, Sasaki J, Ueshima H, Egusa G, Kinoshita M, Shimamoto K, Daida H, Biro S, Hirobe K, Funahashi T, Yokote K, Yokode M: Metabolic Syndrome. J Atheroscler Thromb, 2008; 15: 1-5

19) ÅTRAND PO, Ryhmingy I: A nomogram for calculation of aerobic capacity (physical fitness) from pulse rate during sub-maximal work. J Appl Physiol, 1954; 7: 218-221

20) American College of Sports Medicine: ACSM's Guideline for Exercise Testing and Prescription, 7th Ed (ed by Whaley $\mathrm{MH}$ et al), Lippincott Williams \& Wilkins, Philadelphia, 2005

21) Corbi GM, Carbone S, Ziccardi P, Giugliano G, Marfella R, Nappo F, Paolisso G, Esposito K, Giugliano D: FFAs and QT intervals in obese women with visceral adiposity: effects of sustained weight loss over 1 year. J Clin Endo- 
crinol Metab, 2002; 87: 2080-2083

22) Sawada SS, Lee IM, Takasaki M, Matsuzaki K, Blair SN: Cardiorespiratory fitness and the incidence of type 2 diabetes: prospective study of Japanese men. Diabetes Care, 2003; 26: 2918-2922

23) Yarom R, Zirkin Stämmler G, Rose AG: Human coronary microvessels in diabetes and ischemia. Morphometric study of autopsy material. J Pathol, 1992; 166: 265-270

24) Landsberg L, Troisi R, Parker D, Young JB, Weiss ST: Obesity, blood pressure, and the sympathetic nervous system. Ann Epidemiol, 1991; 1: 295-303

25) Brown MD, Moore GE, Korytkowski MT, McCole SD, Hagberg JM: Improvement of insulin sensitivity by shortterm exercise training in hypertensive African American women. Hypertension, 1997; 30: 1549-1553

26) Chiang CE, Roden DM: The long QT syndrome: genetic besis and clinical implications. J Am Coll Cardiol, 2000; 36: $1-12$

27) Resnick LM: Ionic basis of hypertension, insulin resistance, vascular disease, and related disorder. The mechanism of "Syndrome X". Am J Hypertens, 1993; 6: 123S$134 \mathrm{~S}$

28) Strazzullo P, Barbato A, Galletti F, Barba G, Siani A, Iacone R, D'Elia L, Russo O, Versiero M, Farinaro E, Cappuccio FP: Abnormalities of renal sodium handling in the metabolic syndrome. Results of the Olivetti Heart Study. J Hypertens, 2006; 24: 1633-1639

29) Landin K, Lindgärde F, Saltin B, Wilhelmsen L: Increased skeletal muscle $\mathrm{Na} / \mathrm{K}$-ratio in obese men, but not in women, with glucose intolerance. J Intern Med, 1989; 225: 89-94 